\title{
Autonomy, Interdependence, and Responsibility
}

\author{
W. Michael Reisman ${ }^{\dagger}$
}

No man is an Iland, intire of it selfe; every man is a peece of the Continent, a part of the maine....

If there is a cycle in jurisprudential fashions, then, after an era of Positivism, with intermittent bursts of Natural Law, it had to be time for Historicism. Historicists view law not as the product of conscious choice by a society's members, but as the outcome of a process of growth largely shaped and constrained by historical forces. As each group has its own language or dialect, each has its own unique law. Ubi societas, ibi jus. The law of each group should be allowed to grow, at its own pace and according to its own preordained genetic program, until it reaches the final stage of whatever it is supposed to be. ${ }^{2}$ As for jurists, legislators, and erstwhile social do-gooders, Historicism has curt advice: look but don't touch.

Like other theories, Historicism has authentic insights that are indispensable to understanding law and society. In particular, by emphasizing the distinctiveness of a particular group's legal system, Historicism can reveal differences in perspective and behavior that other approaches might neglect. Weyrauch and Bell, in this fascinating and important study, have used Historicist jurisprudence to its best advantage. In examining the legal system of what they call an "autonomous group," they expose a dimension of law that Positivism handles awkwardly at best. The type of subject matter Weyrauch and Bell have selected is important and relevant. Studies of this type, far from being marginal or exotic "boutique" exercises, are central to understanding the phenomenon of law and to addressing certain urgent policy problems. I admire much of the design and execution of this article and, in particular, the moral argument for a tolerant, pluralistic democracy that animates it.

$\dagger$ Wesley N. Hohfeld Professor of Jurisprudence, Yale Law School. The author acknowledges with gratitude the assistance of Patricia L. Small, J.D. '95.

1. JOHN DONNE, Meditation 17, in DEVOTIONS UpON EMERGENT OCCASIONS 96, 98 (John Spartow ed., Cambridge Univ. Press 1923) (1624).

2. For classic statements of historicist jurisprudence, see generally FRIEDRICH K. VON SAVIGNY, OF THE VOCATION OF OUR AGE FOR LEGISLATION AND JURISPRUDENCE (Abraham Hayward trans., spec. ed. 1986) (1814); Edmund Burke, Speech on a Motion Made in the House of Commons, May 7, 1782, for a Committee To Inquire into the State of the Representation of the Commons in Parliament, in 7 THE WORKS OF THE RIGHT HONORABLE EDMUND BURKE 89, 94-95 (Boston, Little, Brown, \& Co., 3d ed. 1869). For criticism, see generally Morris R. Cohen, History Versus Value, 11 J. PHIL. PSYCHOL. \& SCI. METHODS 701, 705-06 (1914); F.A. HAYEK, THE COUNTER-REVOLUTION OF SCIENCE 64-79 (1955). 
Like so many other theories, however, Historicism can overreach its insights by attempting to explain too much. Ultimately, I believe, Weyrauch and Bell collide with the inherent intellectual boundaries of the Historicist approach to law.

To those who cling to a belief in a unitary and integrating society, the phenomenon of an apparently autonomous legal and political system-such as that of the Roma, the Amish, or Hasidic sects-seems like an exotic survival, or, to those prone to paranoia, like a quiescent virus within the body politic. In fact, the phenomenon is not at all rare. Legal anthropologists, preeminently Leopold Pospisil of Yale, have demonstrated the prevalence, within the apparently unitary "nation-state," of groups with effective political and legal organizations that are independent of and substantively different from those of the state. ${ }^{3}$ Pospisil has shown that these groups need not be proto-states nor aspire to a territorial control-sphere. Moreover, as is the case with gangs, they may work "against" the host society, even be parasitic on it. ${ }^{4}$ While the totalitarian state seeks to delegitimize and suppress all lesser groups, the liberal democratic state, with its commitment to maintaining a private sphere, permits ongoing consociation. Consociation, in turn, leads to the development of smaller, exclusive groups within the political boundaries of the state.

Weyrauch and Bell examine the enduring legal system of the Roma, popularly known as Gypsies. Specifically, they focus upon the Vlax Roma, the largest identifiable group of Gypsies in the United States and the subject of most of the literature on the Roma. The Romani system operates relatively invisibly to most members of the host society, but effectively shapes, holds, and polices the exclusive loyalties of the Roma, while ensuring both the group's collective survival and the transmission of its values from generation to generation. Weyrauch and Bell synthesize the available body of social scientific data and supplement it with the more recent observations of Romani scholars in order to derive a picture of what they call "autonomous lawmaking" among the Roma. That picture, in turn, highlights the extent to which scholarly and public views of the Roma are based on misperceptions.

The authors are primarily interested in drawing general jurisprudential insights from their inquiry. In a number of significant ways, they succeed in developing some original and important ideas. Their scholarly contribution also has timely policy implications for an acute problem that contemporary democracies are only beginning to address systematically: how a society should relate to smaller autonomous communities within its borders. I believe,

3. See Leopold Pospisil, Legal Levels and Multiplicity of Legal Systems in Human Societies, $11 \mathrm{~J}$. CONFLICT RESOL. 2 (1967).

4. Id. at 14 .

5. Given that, over the centuries, the Roma have almost continuously been targets of discrimination and genocidal campaigns, the success of the Romani legal and political system in securing the group's collective survival is remarkable. 
however, that there are also some problems with what they have done, how they have done it, and what they claim their exercise can teach us.

A commentary is ancillary to the principal work it addresses, and this one must be brief. Within these limits, I would like to focus on three areas of the Weyrauch and Bell analysis that, I believe, have been limited by the Historicist approach that the authors have chosen. Part I of this Comment analyzes certain methodological problems of the study. It examines the observational standpoint that Weyrauch and Bell adopt, and suggests that at times the authors fail to compensate for the special research problems that the Roma present. In addition, because Weyrauch and Bell adopt a Historicistic formula-viewing change in Romani law as organic and inexorable-they do not probe more deeply for alternative factors within Romani society that might shape the system they observe. Part II explores the key jurisprudential insights that Weyrauch and Bell draw from their study. In particular, it assesses Weyrauch and Bell's contentions that autonomous law often trumps state law and that societies accept autonomous law more readily than state law. Both observations derive from a Historicistic view of law as a felt experience rather than a conscious choice. Neither appears to have the general validity that the authors ascribe to it. Part III focuses on a policy problem that the Weyrauch and Bell study raises: how should a "host" society relate to autonomous lawmaking by smaller groups within its borders? Weyrauch and Bell do not fully address this question. In part, their analysis is constrained by the Historicist approach they choose, which limits their ability to critique the manner in which the Roma treat members of their own society.

\section{Challenges of Cross-Cultural Observation}

Cross-cultural observation is difficult, not because other groups-cultures, classes, castes, tribes, language and dialect communities, religious communities, gender communities, whatever-are more complex than we are, but because each of us is profoundly shaped, at levels of consciousness so deep that we are unaware of it, by our own culture's categories. We observe others in our terms. In those terms, others can seem incomprehensible or stubbornly and maddeningly irrational. The locus classicus is surely the lament of Shaw's Professor Higgins: "Why can't a woman be like a man?"

Legal scholars try to mitigate, if not solve, this problem by borrowing a number of tools from the social and natural sciences. One of them, the notion of "observational standpoint," may be indispensable for so much as addressing legal phenomena.

Both the reference and content of the term "law" will vary, depending on whether the standpoint is that of a member of the elite or the rankand-file, whether the observer is a member of the system observed 
and has internalized its folklore, myth and miranda, is an outsider or is on the margin. Perception of the same phenomenon may vary depending on the culture, class, gender, age, or crisis-experience of the observer. Even within the legal establishment, reference and content will vary depending on whether the observer is a legislator, a judge, a prosecutor, a juryman, a defense attorney, an accused or a victim. No particular standpoint is more authentic than another, but the scholar must be sensitive to the variations in perception which attend each perspective, try to disengage himself and then carefully determine and consistently maintain his own. ${ }^{6}$

To apply these insights, would-be observers must 1) maintain a consistent observational standpoint; 2) understand themselves and the forces that operate on them; and 3) suspend, insofar as possible, their own culturally supplied categories. None of this is easy. Observers who fail to acknowledge differences in perspective cannot help but paint a distorted picture of others, if not a complete caricature.

In all of his writings, Weyrauch has been acutely sensitive to these preliminary problems of social observation. ${ }^{7} \mathrm{He}$ and Bell take care to identify their standpoint. Because they appreciate how difficult it is for outsiders to grasp the views shared among members of the observed group, they rely heavily on in-group informants, some themselves social scientists. Given the extent of Romani distrust of outsiders, the Roma present unusually difficult research problems in this regard. Weyrauch and Bell resist using the word "primitive" to describe the group under observation, appreciating the intellectually distorting and corrupting superordination lurking in it. Indeed, they are quite willing to refer to certain aspects of their own native systems of law-our law-as tribal. ${ }^{8}$

Though one understands what impels them here, it is difficult to escape the impression that, in trying to deal with the problem of standpoint, the authors may have "overcorrected." In identifying with the Roma, the authors only select affirmatively disposed internal observers. Curiously, no data are supplied by defectors - those who elected to leave the group, for whatever reason, and who, if sought out, could provide critical information. At times, the authors seem to go too far in their efforts to be fair. For example, the authors criticize widespread host-group perceptions of Gypsy behavior as "lawless" by suggesting that the host society draws an arbitrary line between acceptable and unacceptable behavior. The host group treats misleading advertising, but not

6. W. Michael Reisman, Theory About Law: The New Haven School of Jurisprudence, in WISSENSCHAFTSKOLLEG JAHRBUCH 1989/90, at 228, 233 (1991).

7. See, e.g., Walter O. Weyrauch, Gestapo V-Leute (1989); Walter O. Weyrauch, The PERSONALITY OF LAWYERS (1964).

8. Walter O. Weyrauch \& Maureen A. Bell, Autonomous Lawmaking: The Case of the "Gypsies," 103 YALE L.J. 323, 332-33 (1993). 
theft, as an acceptable form of separating a person from his money. ${ }^{9}$ This argument struck me as incomplete and ingenuous. The authors do not probe Gypsy behavior deeply enough to convince the reader that Gypsy activities labeled by the host government as "swindling" are truly as benign as the authors suggest. They fail to demonstrate that the distinctions in the host-group criminal law lack cogency, or that subjecting smaller groups to host-group norms is unnecessary. Nor do the authors show that the discrepant behavior has been elected by the smaller group because there are no other alternatives available to its members. Where members of a pariah group, such as Jews in medieval Europe, are barred from normal commerce and assigned the socially necessary but despised function of "usury," i.e., lending with interest, hatred of that group precisely because it practices usury offends all sense of fairness. But when a host group tolerates or encourages the formation of lesser groups and permits their participation in the market, the question is not what the host group designates as criminal behavior, but whether it applies its prohibitions equally.

By finessing this question, the authors slip from the remarkably consistent disengagement they maintain elsewhere into a defensive posture. That posture, in turn, obstructs the performance of another critical intellectual task. The authors do not address a central policy question: when and how should custodians of inclusive public order sanction behavior that, while viewed as nonconforming by the broader society, is permitted or encouraged by a lesser group? I will return to that question in Part III.

Cross-cultural observation also encounters terminological problems. In crossing boundaries and purporting to describe another system of decision, observers must be able to identify institutions that perform similar functions across cultures, despite differences in structure. At the same time, they must be able to distinguish structurally similar institutions that in fact perform different functions. It is difficult to find a set of terms that will capture these subtleties. To take a mundane example, the word "court" is used in the international political system and in the United States. In each system, however, the "court" may be performing quite different functions and operations. ${ }^{10}$

Even within a single system, there may be discrepancies between what an institution purports to do and what it actually does. In our own legal system, for example, the word "court" is often taken to mean only an institution in which rules made elsewhere are applied to specific disputes. But it is common knowledge that our courts also prescribe law, terminate existing law, provide appraisals of the performance of the aggregate political system or key sectors

9. Id. at 361 .

10. See W. Michael Reisman, Systems of CONTROL IN INTERnational Adjudication and ARBITRATION 11-12, 41-45 (1992). 
of it, and so on. In any given community, decisions may be made in weekly lunches attended by leading businesspeople and the police chief and only then "ratified" by the formal institution of decision, the town council. When law students understand this phenomenon, they have moved away from the notion that the formal institutions are always the effective institutions. Weyrauch and Bell do not appear to recognize this fact. Instead, they do something remarkably conventional in an article that is otherwise so unconventional. They look at the formal institution of the Roma, the kris, and assume that it is the actual arena of decision. Their assumption may or may not be correct, but it should have been tested.

One way of guarding against error in observations in this regard is to focus on decision functions rather than on institutions. ${ }^{11}$ Weyrauch and Bell deploy a limited number of functional terms. For the most part, they use the term "autonomous lawmaking" in their title and throughout their essay. The data Weyrauch and Bell supply, however, indicate that they are talking about much more and much less than lawmaking.

Within the kris there is much more going on than lawmaking. From the descriptions offered by Weyrauch and Bell, a kris terminates existing norms, develops and applies new norms, sometimes mediates, and sometimes performs an arbitral role akin to "alternative dispute resolution." Viewing the kris as a "court" predisposes the observer to look for a "judge," and may obscure more complex decision dynamics. The auditors at a kris express their own views quite openly; the contours of their role in decisionmaking (i.e., the extent to which they are, from the standpoint of an observer, active participants, rather than a Greek chorus on stage only for italics and exclamation points) are not explored. Enough information is available to suggest that it is not useful to apply the term "court" to the range of functions actually performed by a kris and the term "judges" to its personnel.

Weyrauch and Bell are also talking about a social institution that is less than lawmaking. Lawmaking is the major focus of their inquiry, and they succeed in convincing the reader that a Romani legal system and Romani law exist. What Weyrauch and Bell do not address is how that law developed. The authors, true to Historicism, seem to be of the view that Romani law just grew. ${ }^{12}$ That theory tells us very little about how law is created, sustained

11. See generally HaRold D. LAsswell, The Decision Process: SEven Categories of FunCtIONAL ANALYSIS (1956); Myres S. McDougal et al., The World Constitutive Process of Authoritative Decision, in MYREs S. MCDOUGAL \& W. MICHAEL REISMAN, INTERNATIONAL LAW ESSAYS 191 (1981).

12. Many traditional legal systems insist that they just grow naturally. My friend, Francis Deng, who has pioneered the mapping of the legal system among some of the Nilotic tribes of the southern Sudan, recounts an illuminating story about his own research. The vehicle for transmission of much Dinka law is the recitation of folktales. Most tales commence with a formula on the order of "this is an ancient tale ...." Some, however, cannot be ancient, because key events, e.g., participation of Arabs or Europeans or references to tobacco, can be dated rather precisely and often quite recently. When Dr. Deng observed to a chief that the content of the tale could not be very old, the chief laughed and replied, "of course, we changed it." See generally FRANCIS M. DENG, DYNAMICS OF IDENTIFICATION: A BASIS FOR INTEGRATION 
over time, amended, and terminated. Weyrauch and Bell do acknowledge a subtle interaction between the Romani legal system and the host legal system, with each having some degree of influence upon the other. But the authors do not explore the forces within Romani society that shape the legal system. Lawmaking is an ongoing process of communication in which messages of content, authority, and control-intention are modulated in many formal and informal settings. ${ }^{13}$ It is through lawmaking that decisions about "who gets what" are agreed upon and legally endorsed; lawmaking is thus at the intersection of law and politics. This conception of lawmaking highlights an additional weakness of a Historicist approach. If lawmaking is fundamentally political, power is a relevant variable. Any cross-cultural examination of legal systems must account for the variable of power and its operation in the context of the system under observation.

Historicism, however, systematically rejects power considerations. Historicists believe that power is not relevant to studying the development and application of law in a particular society, because law is predetermined rather than the product of interaction among society's members. Weyrauch and Bell do not address power, at least not explicitly. The authors explore the legal system of the Roma, but never the political system; to explore the latter, the authors would have been forced to introduce the question of power. The absence of an explicit treatment of power obstructs a view of the forces underlying certain decisions, leading observers to romanticize the genesis and operation of the legal system under observation. Observers thus tend to ignore the real constraints that operate, and sometimes the ugly violence that is applied. Any legal system that is viewed through a Historicist lens seems far more natural and voluntaristic than our own.

Observation of other legal systems requires a careful balancing of descriptions of what is being said and descriptions of what is actually happening. Achieving this balance is especially difficult when the members of the community under study distrust and systematically exclude outside observers. In relying on informants, it becomes extremely important to continue to probe and question. As Weyrauch and Bell observe, however, conducting such an inquiry among Romani informants is likely to terminate the interview. ${ }^{14}$ Even if it does not, the Romani hostility toward the environing

In the Sudan (1973); Francis M. Deng, Tradmion and Modernization: A Challenge for LaW AMONG THE DINKA OF THE SUdAN (1971); W. Michael Reisman, Folktales and Civic Acculturation: Reflections on the Myths of Dinkaland, in DINKA FOLKTALES: AFRICAN STORIES FROM THE SUDAN 13-21 (Francis M. Deng ed., 1974).

13. These ideas are set out in W. Michael Reisman, Intemational Lawmaking: A Process of Communication, Address Before the American Society of International Law (Apr. 24, 1981), in AMERICAN SOCIETY OF INTERNATIONAL LAW, PROCEEDINGS OF THE 75TH ANNIVERSARY CONVOCATION 101 (1983); and in Myres S. McDougal \& W. Michael Reisman, The Prescribing Function in the World Constitutive Process: How International Law Is Made, 6 YALE J. WORLD PUB. ORD. 249 (1980), reprinted in MCDOUGAL \& REISMAN, supra note 11 , at 355.

14. Weyrauch \& Bell, supra note 8 , at 338 . 
culture is likely to make any inquiry ineffective. The problems are thus especially formidable in the study the authors have undertaken here, and require the development of other inferential devices.

I am not certain that the methods the authors have developed for their special research problem always succeed in striking a balance between perspectives and operations. For example, in describing the process of selection of a "rom baro," or chief, the authors recite that "[t]he main criteria for chiefdom are intelligence and a sense of fairness." 15 It seems difficult to imagine that ordinary politics do not infect the process of selecting the rom baro, given the power he will wield and the indulgences he can distribute. How are Romani chiefs really selected? How do they campaign? What indulgences are distributed? What has been the range of rom baro behavior? A chief may be removed from office, we are told. When has this happened? Why? It is only at the very end of the article - and then in a footnote-that the authors note: "This presentation corresponds to the aspirations of romaniya (Gypsy law). In reality, Romani participants may sometimes be dissatisfied with the actual or potential dispositions of a kris and resort to "extralegal" remedies, such as moving elsewhere." 16 The part of romaniya that is myth system is important, but, from the standpoint of legal analysis, it is incomplete without the corresponding operational code. ${ }^{17}$

Weyrauch and Bell argue that the Romani legal system has played a central role in preserving the relative isolation of the Roma. ${ }^{13}$ Their observation fits with the Historicist emphasis on the permanence of group differences in culture and behavior-and on the unassimilability of certain groups. The authors do not probe deeper; they do not develop an explicit heuristic category for the constitutive process of the Roma. The Roma have survived over several centuries and maintained a degree of autonomy. Presumably, as contexts have changed-from virtual slavery in medieval Romania to virtual liberty in the United States-the process of establishing and maintaining the basic institutions of Romani decision has changed as well in order to facilitate survival.

The authors never describe more broadly the social process within which the Roma interact with the non-Roma. The authors seem to imply that there is a homogeneous "we" ranged against a homogeneous "them." Perhaps this picture might accurately describe the interaction in some central European states in which the majority of the population identifies as a volk or tribe. I would submit that it does not accurately describe the United States, which is a composite of many different groups. The Romani experience in America may be quite different from the Romani experience in other contexts. Likewise,

15. Id. at 352 .

16. Id. at 391 n.276.

17. See W. MiChaEl ReISMAN, Folded LIES: BRIBERY, CRUSADES, AND ReformS 15-36 (1979).

18. Weyrauch \& Bell, supra note 8 , at 373 . 
whether or not the Roma appreciate it, their experiences may not be so different from those of many other Americans-so many of whom "hyphenate" themselves, often with the emphasis on the non-American side of the copula. These observations have some jurisprudential and policy implications that I will consider below.

In all but fully totalitarian systems, certain spheres are regulated by private arrangements and supported by sanctions of relatively low intensity. ${ }^{19}$ Liberal systems refer to these sectors as private spheres, implying that the state adopts a completely hands-off policy toward them. Since these spheres are in fact regulated and supported by sanctions, they are more usefully called the "civic order," which has been described as

the features of social process that are cultivated and sustained by recourse to relatively mild rather than severe sanctions. It is the domain of social process in which the individual person is freest from coercion, governmental or other, and in which a high degree of individual autonomy and creativity prevails. Civic order thus includes all of the processes and institutions of private choice, as distinguished from public decision. ${ }^{20}$

Totalitarian systems do not allow a civic order; autonomous legal and political systems survive perforce stealthily and illegally. In a liberal system, autonomous legal and political systems can operate because the state's policy favors a civic order. Yet even autonomous systems operating within the liberal societies may maintain certain defensive mechanisms-mechanisms once necessary for their survival within totalitarian environments, and now imprinted on the collective memory of their culture. Secretive defensive postures thus remain the essential style of the group, even when they are no longer necessary. In the past, they had been rational; now they may take on a paranoid character and may actually inhibit the fulfillment of other group goals.

Weyrauch and Bell do not develop a category to address the breadth of the civic order in the United States. They acknowledge that the Constitution tends to ignore private lawmaking. ${ }^{21}$ I would take that observation even further: while discriminatory legislation of various types can be found at different levels, the constitutive process of the United States not only tolerates autonomous legal systems, it actually fosters the development of those systems. Because of the position the authors take here, it is difficult to assess whether the Roma survive as an autonomous group because of their traditional strategies or because the environing society has decided that much of Roma

19. See generally MYres S. MCDOUGAL Et AL., Human RightS AND World Public ORDER: THE BASIC POLICIES OF AN INTERNATIONAL LAW OF HUMAN DIGNITY 815-29 (1980).

20. Id. at 815 (footnote omitted). .

21. Weyrauch \& Bell, supra note 8 , at $338,366$. 
organization is appropriate for the civic order. Similarly, it is impossible to determine whether Romani strategies (some of which have severe human value costs that will be discussed below) are contextually rational or have become contextually paranoiac and are, in varying degrees, counterproductive. In short, it would have been useful if the authors had adopted a cross-cultural category for the civic order.

All law is ultimately concerned with the establishment of the minimum conditions of survival, and with the production and allocation of the values that are central to the political calculus of the group concerned: power, wealth, enlightenment, skill, affection, well-being, respect, and rectitude. In describing the Romani legal system, Weyrauch and Bell explore many of these values. Often, however, the authors fail to maintain an observational standpoint, describing the Romani system in terms used by the Roma. Hence, it is difficult for the reader to identify the values (distinctive or not) of the Roma in anything but a negative sense. The reader learns that insiders do not like or trust outsiders; as a corollary, outsiders "pollute" insiders; and, as a corollary, there is a more permissive code for what insiders may do to outsiders. These values are, in varying degree, the essential characteristics of every small group. The authors demonstrate that Romani law promotes group survival. Although group survival is obviously the sine qua non of collective life, I submit that it is, by itself, not enough for appraisal. A legal system can simultaneously promote survival and pursue policies that are extremely costly to some members of society. I will consider this problem in more detail in Part III of this Commentary.

\section{State LaW vs. PRIVATE LaWMaking (Revisited)}

Weyrauch and Bell insist that the law of the state apparatus, as voluminous as it now seems, is a very, very small part of the legal environment. ${ }^{22}$ This proposition is not an especially novel one, even to an arch Positivist, who would simply label all the rest "positive morality"23 and, quite possibly, spend a good deal of time writing and arguing about its relation to law. ${ }^{24}$

Weyrauch and Bell, however, add a very original and important insight: those who wish to achieve desired outcomes in the formal institutions of the state must be aware of and capable of manipulating key parts of the ensemble of informal law. ${ }^{25}$ They may have used the term "law" too broadly, including

22. Id. at 331 .

23. JoHN AUSTIN, THE PROVINCE OF JURISPRUdENCE DETERMINEd AND THE USES OF THE STUdY OF JURISPRUDENCE 12 (Weidenfeld \& Nicolson 1954) (1832).

24. See, e.g., Stephen L. Carter, The Culture of Disbelief (1993); Patrick Devlin, The ENFORCEMENT OF MORALS (1965); H.L.A. Hart, Positivisin and the Separation of Law and Morals, 71 HARV. L. REV. 593 (1958).

25. Curiously, as discussed above, the authors use an essentially statist and institutional conception of law, which would seem anachronistic in general and particularly at odds with a study of informal law. 
a range of cultural factors that are manipulable but not usefully considered "law" or "law-made."26 But that is debatable, and the insight stands. It has implications for legal practice and even the most anti-intellectual type of legal education; the authors make this point very well. I am not sure one has to study Romani law in order to glean this insight or, indeed, that this insight actually derives from this particular study. Nonetheless, Weyrauch and Bell make an important point, and I hope that they go on, in other publications, to elaborate the methods for implementing it.

As a corollary, Weyrauch and Bell suggest that autonomous law virtually always prevails over the law of the state. ${ }^{27}$ This proposition seems too broad. Surely we need to know more about the relationship between autonomous law and the law of the state before we can say if and when one trumps the other. For example, we would need to assess the intensity of demand for each of the competing norms from these different sources, the consequences of their application in particular cases, and the relative power positions of different groups.

Also unconvincing is the authors' attempt to refashion Savigny's notion of law as a shared experience: "[t]hat which binds them into one whole is the common conviction of the people, the kindred consciousness of an inward necessity, excluding all notion of an accidental and arbitrary origin."28 The authors argue that members of a group absorb and accept private legal traditions more readily than laws imposed by the state. ${ }^{29}$ They suggest that among the Roma, as elsewhere, changes in law come about organically and imperceptibly, and that if such changes were explicitly noted, they might be rejected. ${ }^{30}$ Drawing on Weyrauch's pathbreaking study on the generation of a microlegal system among volunteers in a NASA isolation experiment, ${ }^{31}$ the authors imply that new rules of a system of private lawmaking should not be articulated. ${ }^{32}$

This Historicistic formulation, which treats law as a sort of felt experience rather than conscious choice, seems questionable. The notion that new rules should not be articulated because articulation would slow the process of change may hold true in the context of rules that are inconsistent with the myth system; ${ }^{33}$ I think that this is Professor Funk's approach, ${ }^{34}$ though his formulation confuses norms and behavior. In my own research, I found that

26. See Nicholas S. TimashefF, AN InTRoduction to the Sociology of LAW (1939).

27. Weyrauch \& Bell, supra note 8 , at 331 .

28. SAVIGNY, supra note 2, at 24 (quoted in Weyrauch \& Bell, supra note 8, at 375 n.222).

29. Weyrauch \& Bell, supra note 8 , at 375 .

30. Id, at 375-76.

31. Walter O. Weyrauch, The "Basic Law" or "Constitution" of a Small Group, 27 J. Soc. Issues 49, app. at 59 (1971).

32. Weyrauch \& Bell, supra note 8, at 376; see also DAvID A. FUNK, GRouP DYNAMIC LAW: INTEGRATING CONSTITUTIVE CONTRACT INSTITUTIONS 73-75 (1982).

33. Reisman, supra note 13 , at 33-36.

34. Group DynamiC Law: EXPosition AND PractiCE, 178 (David Funk ed., 1988). 
while accepted violations of taboos were not to be discussed openly, they were the subject of discussion, validation, and confirmation among people who trusted each other, on the order of: "sure, you're not supposed to do that, but ...." I do not think the hypothesis that Weyrauch and Bell have formulated has the general validity they attribute to it.

Nor is the authors' discussion of the functions and virtues of memory persuasive. They suggest that knowledge of unwritten law is acquired "casually and almost effortlessly,"35 and then "absorbed into the individual's psyche." ${ }^{36}$ These observations seem to overstate the ease with which information is acquired and retained. At certain periods of human history, very complex mnemonic devices were devised to facilitate memorization; those devices still required major investments of time and energy. ${ }^{37}$ The mnemonics were discarded when better tools became available. Obviously, people in different contexts perceive and retain memories of a different universe. I have no way of knowing whether a nonliterate member of a folk society remembers more than a literate member of an advanced industrial civilization-indeed, whether the nonliterate even remembers more customary law than his literate counterpart. Nor can I see any advantages to nonwritten law, but there are many disadvantages. There may be no need for jurists in a society where everyone remembers and "knows" the law. (Actually, as the authors remark, without intending humor, much remembered law is always being forgotten. $)^{38}$ It is unclear, however, that a system without jurists is indeed preferable. Weyrauch and Bell themselves record that among the Roma, functional "lawyers" sometimes plead at kris. ${ }^{39}$

Finally, a word must be said about Positivism. At a theoretical level, Weyrauch and Bell offer a critique of Positivism in two ways. First, for contemplative purposes, it is a jurisprudence that fails to bring into focus the bulk of the law, which is produced privately or autonomously. Second, for manipulative purposes, as the authors show, the advocate has less chance of prevailing, even in the fora of the state, if he or she fails to understand and use autonomous law.

While both of these points are well taken, something remains to be said for Positivism that I believe the authors overlook. Where there are many groups coexisting in a territory, each may have its own unique vision of past and future, its own language or dialect, its own values, and its own mysterious law, emerging, as group members are encouraged to believe, as a sort of excrescence of the group experience. Superordinating the law of any one group over the others is a prescription for endless conflict. Redefining law in secular

35. Weyrauch \& Bell, supra note 8 , at 374 .

36. Id. at 375 .

37. Jonathan D. Spence, The Memory Palace of MatTeo RicCi 1-23 (1984).

38. Weyrauch \& Bell, supra note 8 , at 375 .

39. Id. at 356 n.145. 
and entirely ahistorical terms, as authoritative policy clarification and implementation by the state apparatus, certainly has intellectual limits. Nevertheless, it permits the law to take on a constructive mediating role between the different groups that constitute the community. This explanatory power was the attraction of Positivism early this century in a central Europe of contending ethnicities, ${ }^{40}$ and, in a different configuration of conflict, in nineteenth century England. It is, in no small part, the continuing attraction of Positivism as an ideology in contemporary America. ${ }^{41}$ It promises some protection for all groups, including the Roma.

\section{AUTONOMY AND HUMAN RIGHTS}

The fundamental policy question that emerges from the Weyrauch and Bell study is how a purportedly liberal host society-at once homogeneous and heterogeneous-should relate to groups with autonomous legal and political systems operating in its midst. The question goes beyond the issues raised by the authors and beyond the Roma, and raises a number of subsidiary questions. Should there be insistence on a national language? Should the state establish a minimum content-scientific or otherwise-for public education? How should the inclusive community, through the apparatus it establishes to provide security, relate to innovative religious groups or "cults," to use a term that implicitly rejects them? How should the broader legal system relate to microlegal systems-like courtship rituals-that were formerly quite private but are now deemed to affect values important to collective life?

These dilemmas are not especially "American" ones. Across Europe, the question of how larger social systems and smaller groups that resist assimilation (and/or whose assimilation is resisted by the larger group) should relate to one another has moved again to the political forefront. In many parts of central Asia and the Far East, wars are being fought over this issue. Internationally, the relationship of states to the "indigenous peoples" within their borders is now the subject of a number of initiatives to forge a common policy expressed in multilateral conventions. ${ }^{42}$ When these claims have been made by the elites of the smaller groups, they have been framed in terms of "group rights." This claim is problematic within a human rights codex that was originally conceived in terms of the rights of the individual.

40. HaNS Kelsen, General THEORY OF LAW AND STATE 445-46 (Anders Wedberg trans., 1973).

41. JUdITH N. SHKLAR, LEgalisM: LAW, MORALS AND POLITICAL TRIALS 37-38 (1986).

42. See, e.g., Discrimination Against Indigenous Peoples: First Revised Text of the Draft Universal Declaration on Rights of Indigenous Peoples, U.N. Doc. E/CN.4/Sub.2/1992/33 (1992). For the leading U.N. study on indigenous communities, see JOSE R. MARTÍNEZ COBO, STUDY OF THE PROBLEM OF DisCRIMINATION AGAINST INDIGENOUS PoPULATIONS, U.N. Doc. E/CN.4/Sub.2/1986/7/Add.4, U.N. Sales No. E.86.XIV.3 (1987). 
Nor are these dilemmas uniquely modern. The history of our species is a history of interactions between groups; much of it has concerned patterns of superordination and subordination. The greatest of modern empires, the Ottoman, dealt effectively and economically with the problem of how to structure relations between groups. The Osmanlis retained political power in the hands of a self-perpetuating elite and developed the millet or nationality system for religious minorities. Under this system, the Osmanlis granted a high degree of autonomy to individual communities, each of which could organize and manage itself legally and politically under autonomous institutions and leadership. ${ }^{43}$

Our civilization wrestled with the problem in the seventeenth century. The Peace of Westphalia, with its innovative tolerance of different religions, represented the basic structure of a solution. ${ }^{44}$ Its implementation, however, required adaptations at both the legal and jurisprudential levels. Much of early English Positivism was an attempt to develop an appropriate psychological attitude for this new and complex system. ${ }^{45}$ The policy established in the seventeenth century seems to be undergoing a gradual revision. As many new faiths begin to operate in the United States, some home-grown-the so-called "cults"-some imported more recently-Buddhism, Hinduism, Voodun, Santeria, Islam in its various sects, and so on-the increasingly frequent reference to "Judeo-Christian" roots may carry with it, whether or not intentionally, a policy of intolerance for the newcomers. Hence, Weyrauch and Bell's remarkable legal portrait of the Roma forces us to inquire about the relation that should exist between "us" (however one decides who "we" are) and "them."

The scholar who faces this question must explicitly change roles and intellectual equipment. From a disengaged observer who was only trying to understand and contemplate certain phenomena, the scholar, while drawing upon the results of systematic inquiry, now becomes a citizen-advocate. Weyrauch and Bell do not explicitly address this issue. The authors counsel against measuring Gypsy culture against our own. They note that non-Gypsy scholars "have failed to wrestle with their own deeply ingrained beliefs in the superiority of their cultural values, including the notions that objective scholarship and science are possible and that some neutral concept of merit can determine the value of other cultures. ${ }^{946}$ The authors may be correct that a preference for one's own culture limits one's performance of tasks related to perception. Some tasks, however, are perforce appraisive and begin to shift

43. See NORMAN ITZKowITZ, OTTOMAN EMPIRE AND ISLAMIC TRADITION 58-59 (1980); JoHN P. KinRoss, THE OTtOMAN CENTURIES 112-13 (1977).

44. MCDougal ET AL., supra note 19 , at 670 .

45. W. Michael Reisman, The Tormented Conscience: Applying and Appraising Unauthorized Coercion, 32 EMORY L.J. 499 (1983).

46. Weyrauch \& Bell, supra note 8 , at 338,366 (footnote omitted). 
into policy prescription. Even here, the authors' admonition about the intellectual hazards of cultural narcissism is well taken. But some choices must ultimately be made.

The typical way of analyzing this problem has been to focus on the perceived minimum order requirements of the environing community. Rarely has this analysis been undertaken in a rigorous and disciplined fashion; often, it has been and continues to be the vehicle for the recurring phenomena of majority paranoia, parochialism, and xenophobia. These phenomena form the substructure for nationalist and racist hysteria, the imposition of a single language, forced name changes, official efforts to obliterate the cultures and religions of smaller groups, and, ultimately, demands for purging the body politic of "foreign contamination." This is a spiral that can conclude in genocide ${ }^{47}$ Minorities concerned with resisting assimilation and maintaining their identity and group integrity, among them the Roma, will be the targets.

Weyrauch and Bell, like all good and thoughtful people who have experienced this century, are wary of judging in these terms. They refuse to judge. The authors view the Romani system not as the product of a conscious choice on the part of the Roma, but as the product of forces over which the Roma have no control. Thus, the authors believe we should first try to understand "them," whoever they may be, understand ourselves, and practice tolerance. I understand their position. It is based in part on humility in acknowledging that much of the way "we" organize our individual and collective lives is neither natural nor particularly rational, but rather a cultural choice largely shaped by historical forces that we deem to be natural, necessary and, usually, right. It is based in part on curiosity and respect for the way others organize their individual and collective lives. Theirs is a humane and tolerant position. It may be a responsible personal one. It is, in my view, an indispensable input for the development of a policy position, but not in itself an adequate policy position.

In an interdependent, global industrial and science-based civilization, no group is truly autonomous. Autonomy in the modern world is relative and contingent on choices-choices about the degree to which smaller groups may discharge themselves from the reach of general community norms and apply their own. These choices are made by members of would-be autonomous groups, by the larger groups within which they exist, and the larger groups within which they exist. An important part of contemporary international law concerns itself with the establishment and protection of territorially and nonterritorially organized groups, and the international protection of the human rights of those who find themselves, willingly or otherwise, in their midst. International law prescribes some basic principles that can guide choices about the degree of autonomy a smaller group may exercise. Because this process

47. Raul Hilberg, The Destruction of THE EuRopean Jews 760-62 (1961). 
and the policies it has generated to guide decision do not derive from the positive law of a single state, but seek to limit and guide the behavior of all state elites, the arrangements that emerge between smaller groups and states should be less susceptible to the abuses that were characteristic of entirely nationalistic treatment of distinct minorities. In most general terms, the principles call for the protection of individual rights and ordain a network of claims for protection and opportunity that every person in the world is entitled to make against whoever-government or otherwise-exercises power over them. ${ }^{48}$ One of these claims is the right of association and group formation as an instrument for the fulfillment of personal rights. The rights of group formation and the tolerated authority of group elites over their members extend insofar as they are indispensable for the achievement of individual rights. They cannot be justified if their effect is to abridge or limit basic individual rights.

The legal and political practices of any group-majority or minority; state or non-state; territorially or non-territorially based; in the United States, China, or Iran; Christian, Islamic, Jewish or Hindu fundamentalist; the Roma, the Unification Church, or the Branch Davidians-can no longer be insulated from appraisal simply and exclusively by invoking talismanic terms like "sovereignty," "domestic jurisdiction," "tradition," "history," the supposed wills of assorted divinities, "the way we have always done things," "nonpollution," "autonomy," or as alleged preconditions for "group continuity." I submit that the practices of all groups must be appraised in terms of the international code of human rights. Deviations from that code do not signal the termination of the group, but will lead to the insistence that the discrepant practices be adjusted to conform with international standards.

From an international legal standpoint, the Roma are entitled to form a group, to have their own legal system, and to seek protection, at the national and international levels, from violations of those rights. Everyone is entitled to form groups. Or to opt out of them. But some of the Romani elite's specific claims for authority over group members are not compatible with international human rights standards.

The elites of exclusive groups cannot deprive minors subject to their control a right to education on the ground that education is likely to lead to their ritual pollution or will enable them to determine for themselves whether they wish to spend their lives within the group or affiliate with another. Romani practices that effectively subordinate women and train them to believe that for most of their lives they are "polluted" and sources of pollution for others are not compatible with the international human rights code. The

48. See, e.g., Universal Declaration of Human Rights, G.A. Res. 217A, U.N. GAOR, 3d Sess. pt.1, at 71, U.N. Doc. A/810 (1948); Intemational Covenant on Civil and Political Rights, Dec. 16, 1966, G.A. Res. 2200, U.N. GAOR, 21st Sess., Supp. No. 16, at 52, U.N. Doc. A/6316 (1967) (entered into force Mar. 23, 1976); International Covenant on Economic, Social and Cultural Rights, Dec. 16, 1966, G.A. Res. 2200, U.N. GAOR, 21st Sess., Supp. No. 16, at 49, U.N. Doc. A/6316 (1967) (entered into force Jan. 3, 1976). 
contention that suppressing marime practices that subordinate women may weaken Romani cohesion is about as compelling as the argument that prohibiting female mutilation in East Africa will undermine the indigenous cultures of the peoples who practice it. Even if such contentions were not so preposterous, the deprivations they impose on weaker members of the group concerned are no longer tolerable.

\section{CONCLUSION}

Weyrauch and Bell have taught us to see the Roma as human beings, with a vision of past and future as distinctive as any other and a remarkable and resilient legal system designed to protect the values they cherish. The subtext is that we all have an urgent interest in the maintenance of a meaningful civic order. All of us are always joining and forming groups as an instrument for the fulfillment of our individual lives. Each of these groups must demand some space-some autonomy-to secure its objectives. All of us will be diminished if we do not allow and protect, for all groups, that space and the lawmaking that can flourish within it. Yet none of these groups is completely autonomous. We all continue, always, to be members of ever larger groups and, ultimately, the global community of mankind under the empire and protection of its law. 